This article is licensed under the Creative Commons Attribution-NonCommercial 4.0 International License (CC BY-NC) (http://www.karger.com/Services/OpenAccessLicense). Usage and distribution for commercial purposes requires written permission.

\title{
Rectal Bleeding after Insertion of a Percutaneous Endoscopic Gastrostomy Tube
}

\author{
Ghadeer Alhazmi $^{\mathrm{a}} \quad$ Mroj Alsabri $^{\mathrm{a}}$ Shahad Alsuwat ${ }^{\mathrm{a}} \quad$ Adnan Al-Zangabi $^{\mathrm{b}}$ \\ Abdulaziz Al-Zahranic ${ }^{c}$ Mohammed Kareemulla Shariff ${ }^{b}$ \\ aCollege of Medicine, Umm Al-Qura University, Makkah, Saudi Arabia; bigestive \\ Diseases, Liver Center and Advanced Endoscopy Center, King Abdullah Medical City, \\ Makkah, Saudi Arabia; 'Specialist Surgical Center, King Abdullah Medical City, \\ Makkah, Saudi Arabia
}

\section{Keywords}

Percutaneous endoscopic gastrostomy $\cdot$ Complication $\cdot$ Rectal bleeding

\begin{abstract}
latrogenic injury to an internal organ such as the stomach, colon, small bowel, or liver after percutaneous endoscopic gastrostomy (PEG) tube insertion is a rare complication. We present a case of rectal bleeding due to colon injury during PEG tube placement. This required urgent exploratory laparoscopic surgery with segmental resection of the transverse colon and replacement of the PEG tube. Postoperatively, the patient significantly improved with time and tolerated PEG tube feeding.

(C) 2020 The Author(s)

Published by S. Karger AG, Basel
\end{abstract}




\section{Case Reports in Gastroenterology}

\begin{tabular}{l|l}
\hline Case Rep Gastroenterol 2020;14:637-643 \\
\hline DOI: 10.1159/000510164 & $\begin{array}{l}\text { @ 2020 The Author(s). Published by S. Karger AG, Basel } \\
\text { www.karger.com/crg }\end{array}$ \\
\hline
\end{tabular}

Alhazmi et al.: Rectal Bleeding after Insertion of a PEG Tube

\section{Introduction}

Percutaneous endoscopic gastrostomy (PEG) tube placement is one of the most common endoscopic therapeutic procedures performed worldwide. It was described by Ponsky and Gauderer [1] in 1980. PEG is a specialist technique that creates an artificial access route to the stomach through the skin and the anterior abdominal wall to provide mid- to long-term enteral nutrition, medication, hydration, and stomach decompression $[2,3]$. The list of indications for PEG use has expanded over the years; apart from nutrition and survival, they now include improvement in quality of life and palliation in malignancy. Common indications include dysphagia due to neurological sequelae, esophageal or head and neck cancer, and functional or anatomical insult to the upper gastrointestinal tract [3]. In addition, it is used to support nutrition in cases of cystic fibrosis, congenital anomalies, and inflammatory bowel disease [4].

A PEG tube can be inserted endoscopically, surgically, or radiologically. However, due to its ease, cost-effectiveness, and safety profile, as well as avoidance of radiation, the endoscopic method has emerged as the preferred method $[2,4]$. Appropriate placement of the PEG tube is imperative to avoid complications. Three different techniques have been described for endoscopic insertion: the "pull" approach as reported by Ponsky and Gauderer, which was modified to some degree to add a new "push" procedure, as well as a further refinement, leading to the "introducer" technique [5], a new, simplified, and cost-effective technique [6].

The pull approach remains the preferred one, and it was used in our case. This technique requires an assistant to the endoscopist. Briefly, one of the key steps of this technique is the diligent location of the site of PEG tube insertion, achieved via good transillumination of the stomach by endoscopic light by the assistant. The assistant then indicates this site by putting his finger on it, creating an indentation in the stomach wall that is corroborated by the endoscopist. Once the site is confirmed, it is made aseptic and a trocar is punctured through while the tip is being visualized endoscopically. A wire is threaded through this trocar, grasped endoscopically, and pulled out of the mouth. The PEG tube is loaded onto the wire and pulled by the assistant through the puncture site and fastened to the abdominal wall [7].

Although it is usually considered a safe procedure, PEG tube insertion may cause complications. These can be anything from minor complications like simple wound infections, tube blockage, and simple pneumoperitoneum to life-threatening complications like buried bumper syndrome, perforation of the bowel, and even death; however, this is rare and seen mainly in elderly patients with comorbidities [4]. Use of the correct technique of PEG tube insertion with proper positioning of the external fixation device, suitable prophylactic antibiotics, and daily tube care are essential to prevent the occurrence of severe complications [2]. Here, we present the rare complication of iatrogenic lower gastrointestinal bleeding due to colon injury during PEG tube placement.

\section{Karger'=}




\section{Case Reports in Gastroenterology}

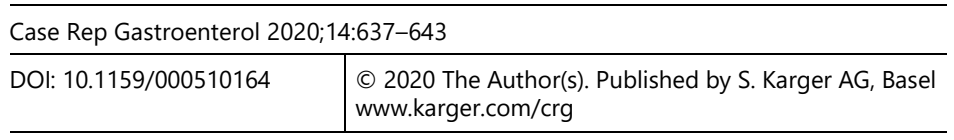

Alhazmi et al.: Rectal Bleeding after Insertion of a PEG Tube

\section{Case Presentation}

An 80-year-old male patient with known diabetes mellitus and essential hypertension presented with a stroke (bilateral thalamic, left occipital, and brain stem), which left him quadriplegic, bedridden, and dysphagic. To support nutrition, nasogastric tube feeding was initiated and continued for 3 weeks. There was no improvement in his dysphagia and a prolonged need for nutrition was recognized. A decision to insert a PEG tube was taken at a joint multidisciplinary meeting of the nutritionist, gastroenterologist, and primary team physician.

A $20-$ Fr $(6.7-\mathrm{mm})$ tube was inserted using the pull-through technique, and the position of the bumper was confirmed endoscopically in the body of the stomach. No immediate technical difficulties or postprocedural complications were encountered. His vital signs and complete blood count remained stable before and after the procedure, as shown in Table 1.

Ten days later, the patient developed bleeding per rectum, which initially was intermittent, bright-red blood mixed with stool. As this was not associated with any instability of his vital signs or change in complete blood count, an elective colonoscopy was requested. However, $48 \mathrm{~h}$ later the rectal bleeding became profuse, with passing of large clots. Apart from tachycardia, the blood pressure remained stable, as shown in Table 2. On examination, the abdomen was soft with normal bowel sounds and no distention or tenderness. A rectal examination revealed fresh red blood with no palpable mass. His hemoglobin level dropped from 13.4 to $9.6 \mathrm{mg} / \mathrm{dL}$, and his white cell count increased to $18.3 \times 10^{9} / \mathrm{L}$. Due to ongoing significant rectal bleeding with clots, it was decided to perform an endoscopy, starting with a gastroscopy to rule out an upper gastrointestinal source and then proceeding to colonoscopy.

\section{Investigations}

Upper endoscopy showed no evidence of upper gastrointestinal bleeding, and the PEG tube was noted to be in situ with no evidence of bleeding or any blood until the second part of the duodenum (Fig. 1). Colonoscopy showed blood clots in the rectum up to the transverse colon, where a white glistening foreign body was noted. The PEG tube was clearly identified after cleaning and washing to be traversing the transverse colon (Fig. 2).

\section{Treatment}

Due to ongoing bleeding, the patient underwent urgent exploratory laparoscopic surgery. The PEG tube was found traversing the anterior abdominal wall and the stomach, with the transverse colon interposed. Segmental transverse colon resection was performed, with removal of the PEG tube and placement of a new one.

Outcome and Follow-Up

Following the operation there was no more rectal bleeding, and the patient tolerated feeding through the PEG tube without any complications.

\section{Karger'=}




\section{Case Reports in Gastroenterology}

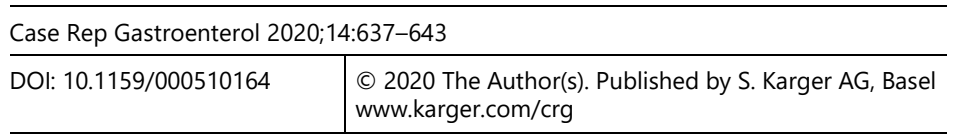

Alhazmi et al.: Rectal Bleeding after Insertion of a PEG Tube

\section{Discussion and Conclusion}

PEG tube placement is one of the safest procedures, with low rates of mortality and morbidity. The overall complication rate varies between 4 and $23 \%$, with most of the complications being minor $[3,8]$. The most frequent complications include wound infection, tube blockage or dislodgment, peristomal leakage, pneumoperitoneum, bleeding, aspiration pneumonia, buried bumper syndrome, and, rarely, necrotizing fasciitis [2]. Injuries to an internal organ such as the stomach, colon, small bowel, or liver have been reported, and they can present during insertion or later as bleeding, pneumoperitoneum, leakage, fistula, or peritonitis [2].

A very rare complication like gastrocolocutaneous fistula can occur when the PEG tube is inadvertently placed through the colon into the stomach. It can present acutely as abdominal distention, fever, pneumoperitoneum, or ileus $[2,9]$. However, most cases remain asymptomatic and are discovered late following tube replacement when the tube is misplaced into the colon, leading to diarrhea or feculent discharge at the PEG site [10]. A higher-than-usual anatomical location of the colon and gastric distention due to excess air may interpose the transverse colon between the stomach and the abdominal wall, causing the PEG tube to transverse the colon during insertion [9-11]. A good PEG tube insertion technique with a combination of excellent transillumination, careful visualization via finger indentation of the gastric wall, and appropriate insufflation may help prevent this from happening [2]. In addition, using a "safe tracts" technique at the time of insertion - by aspirating the syringe, looking for any air before the appearance of the needle in the stomach, and by placing the head up to displace the colon caudally - may avert this complication $[8,12]$.

Our case highlights an unusual presentation of gastrocolocutaneous fistula following PEG tube insertion in the form of rectal bleeding that had not been reported before. It aims to increase awareness of this complication and its varied presentations, as well as to emphasize the need for good PEG tube insertion techniques.

\section{Statement of Ethics}

The patient gave written informed consent to publish the case (including publication of images).

\section{Conflict of Interest Statement}

The authors have no conflicts of interest to declare.

\section{Funding Sources}

There was no financial support. 


\section{Case Reports in Gastroenterology}

Case Rep Gastroenterol 2020;14:637-643

DOI: $10.1159 / 000510164$

(C) 2020 The Author(s). Published by S. Karger AG, Basel www.karger.com/crg

Alhazmi et al.: Rectal Bleeding after Insertion of a PEG Tube

\section{Author Contributions}

G. Alhazmi participated in sequence alignment, coordination and data collection, wrote the paper, and finalized the final draft of the manuscript. M. Alsabri and S. Alsuwat participated in data collection and wrote the paper. A. Al-Zangabi and A. Al-Zahrani reviewed the final draft of the manuscript. M.K. Shariff participated in sequence alignment and coordination and reviewed the final draft of the manuscript. All authors read and approved the final manuscript.

\section{References}

1 Ponsky JL, Gauderer MW. Percutaneous endoscopic gastrostomy: a nonoperative technique for feeding gastrostomy. Gastrointest Endosc. 1981 Feb;27(1):9-11.

2 Hucl T, Spicak J. Complications of percutaneous endoscopic gastrostomy. Best Pract Res Clin Gastroenterol. 2016 Oct;30(5):769-81.

3 Itkin M, DeLegge MH, Fang JC, McClave SA, Kundu S, Janne d'Othee B, et al.; Interventional Radiology and American Gastroenterological Association; American Gastroenterological Association Institute; Canadian Interventional Radiological Association; Cardiovascular and Interventional Radiological Society of Europe. Multidisciplinary practical guidelines for gastrointestinal access for enteral nutrition and decompression from the Society of Interventional Radiology and American Gastroenterological Association (AGA) Institute, with endorsement by Canadian Interventional Radiological Association (CIRA) and Cardiovascular and Interventional Radiological Society of Europe (CIRSE). J Vasc Interv Radiol. 2011 Aug;22(8):1089-106.

4 Rahnemai-Azar AA, Rahnemaiazar AA, Naghshizadian R, Kurtz A, Farkas DT. Percutaneous endoscopic gastrostomy: indications, technique, complications and management. World J Gastroenterol. 2014 Jun;20(24):7739-51.

5 Sacks BA, Vine HS, Palestrant AM, Ellison HP, Shropshire D, Lowe R. A nonoperative technique for establishment of a gastrostomy in the dog. Invest Radiol. 1983 Sep-Oct;18(5):485-7.

6 Russell TR, Brotman M, Norris F. Percutaneous gastrostomy. A new simplified and cost-effective technique. Am J Surg. 1984 Jul;148(1):132-7.

7 Löser C, Aschl G, Hébuterne X, Mathus-Vliegen EM, Muscaritoli M, Niv Y, et al. ESPEN guidelines on artificial enteral nutrition - percutaneous endoscopic gastrostomy (PEG). Clin Nutr. 2005 Oct;24(5):848-61.

8 Anderloni A, Di Leo M, Barzaghi F, Semeraro R, Meucci G, Marino R, et al. Complications and early mortality in percutaneous endoscopic gastrostomy placement in lombardy: a multicenter prospective cohort study. Dig Liver Dis. 2019 Oct;51(10):1380-7.

9 Ahmad J, Thomson S, McFall B, Scoffield J, Taylor M. Colonic injury following percutaneous endoscopicguided gastrostomy insertion. BMJ Case Rep. 2010;2010:bcr0520102976.

10 Friedmann R, Feldman H, Sonnenblick M. Misplacement of percutaneously inserted gastrostomy tube into the colon: report of 6 cases and review of the literature. JPEN J Parenter Enteral Nutr. 2007 NovDec;31(6):469-76.

11 Lee J, Kim J, Kim HI, Oh CR, Choi S, Noh S, et al. Gastrocolocutaneous Fistula: An Unusual Case of Gastrostomy Tube Malfunction with Diarrhea. Clin Endosc. 2018 Mar;51(2):196-200.

12 Foutch PG, Talbert GA, Waring JP, Sanowski RA. Percutaneous endoscopic gastrostomy in patients with prior abdominal surgery: virtues of the safe tract. Am J Gastroenterol. 1988 Feb;83(2):147-50. 


\section{Case Reports in Gastroenterology}

Case Rep Gastroenterol 2020;14:637-643 (c) 2020 The Author(s). Published by S. Karger AG, Basel www.karger.com/crg

Alhazmi et al.: Rectal Bleeding after Insertion of a PEG Tube

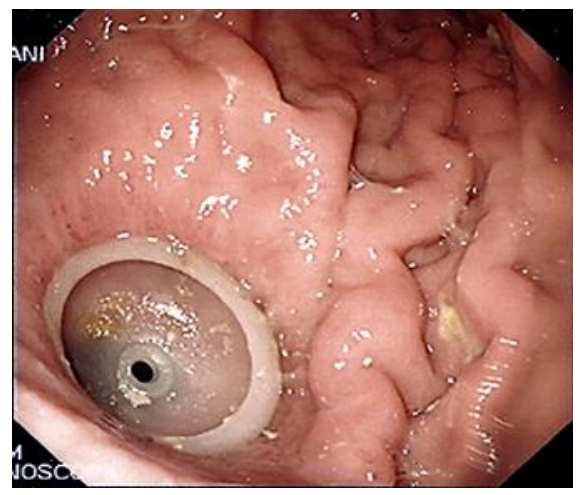

Fig. 1. Upper endoscopy image showing the percutaneous endoscopic gastrostomy tube in situ.
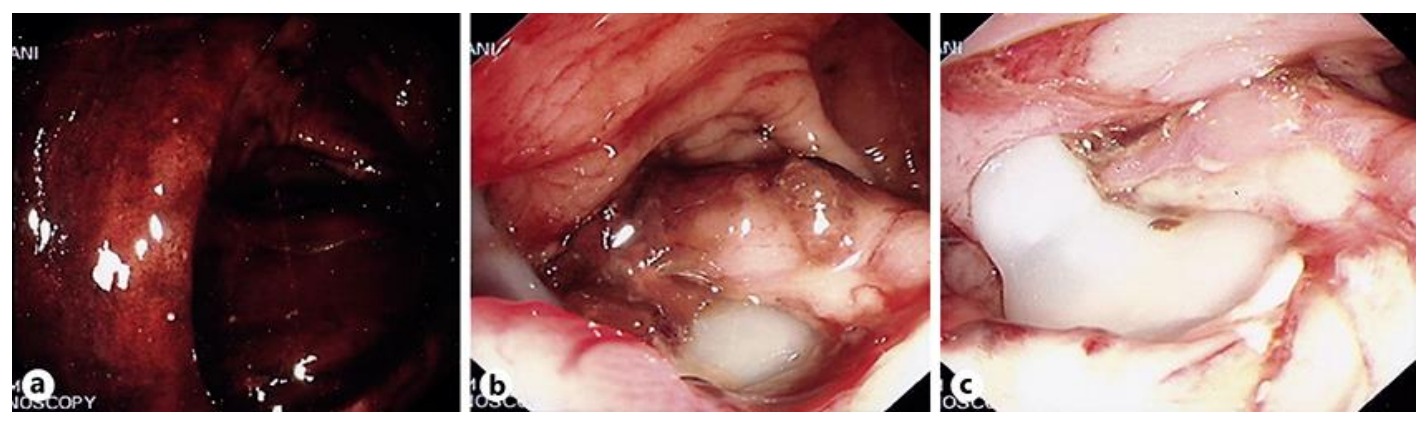

Fig. 2. Colonoscopy showed that the percutaneous endoscopic gastrostomy tube was traversing the transverse colon. a Initial view of the transverse colon with fresh blood. b, c Following washing, the white glistening percutaneous endoscopic gastrostomy tube was visible (b), more obvious on further washing (c).

Table 1. Patient's CBC and vital signs before PEG tube insertion

\begin{tabular}{llll}
\hline CBC & & Vital signs \\
\hline Hemoglobin & $13.4 \mathrm{~g} / \mathrm{dL}$ & Heart rate & $96 \mathrm{bpm}$ \\
White blood cell count & $14.6 \times 10^{9} / \mathrm{L}$ & Oxygen saturation & $99 \%$ \\
Platelet count & $297 \times 10^{9} / \mathrm{L}$ & Blood pressure & $124 / 82 \mathrm{~mm} \mathrm{Hg}$ \\
& & Temperature & $36.9^{\circ} \mathrm{C}$ \\
& & Respiration rate & $20 \mathrm{breaths} / \mathrm{min}$
\end{tabular}

CBC, complete blood count; PEG, percutaneous endoscopic gastrostomy. 
Table 2. Patient's CBC and vital signs after rectal bleeding

\begin{tabular}{llll}
\hline CBC & & Vital signs \\
\hline Hemoglobin & $9.6 \mathrm{~g} / \mathrm{dL}$ & Heart rate & $120 \mathrm{bpm}$ \\
White blood cell count & $18.3 \times 10^{9} / \mathrm{L}$ & Oxygen saturation & $97 \%$ \\
Platelet count & $290 \times 10^{9} / \mathrm{L}$ & Blood pressure & $121 / 81 \mathrm{~mm} \mathrm{Hg}$ \\
& & Temperature & $37.2^{\circ} \mathrm{C}$ \\
& & Respiration rate & $27 \mathrm{breaths} / \mathrm{min}$ \\
\hline
\end{tabular}

CBC; complete blood count. 